\title{
Magnet Shape Optimization of Two-Layer Spoke-Type Axial Flux Interior Permanent Magnet Machines
}

\author{
Feng Chai, Yunlong Bi (D) and Yulong Pei * \\ School of Electrical Engineering and Automation, Harbin Institute of Technology, Harbin 150001, China; \\ chaifeng@163.com (F.C.); biyunlongemail@gmail.com (Y.B.) \\ * Correspondence: peiyulong@hit.edu.cn; Tel.: +86-451-8640-3480
}

Received: 20 November 2017; Accepted: 18 December 2017; Published: 23 December 2017

\begin{abstract}
In this paper, the two-layer spoke-type (TLST) axial flux interior permanent magnet (AFIPM) machine is proposed. Simple flux barriers are added to optimize the air gap flux density, in which way there is no need to change the surface of the rotor. The optimization principle is revealed and the advantages of the TLST AFIPM machine compared with the spoke-type (ST) AFIPM machine are clarified. An optimization design process based on magnetic equivalent circuit combined with idealized and improved air gap flux density waveform is proposed, in which way the calculation time is saved by avoiding an excess of finite element method (FEM) simulations. Finally, 3D FEM simulation is adopted to verify the optimization results.
\end{abstract}

Keywords: axial flux interior permanent magnet machine; air gap flux density; two-layer spoke-type permanent magnet; flux barrier

\section{Introduction}

Axial flux permanent magnet (AFPM) machines have some noticeable benefits compared with the conventional radial flux permanent magnet (RFPM) machines, such as higher power density, higher torque density and compact construction. As a result, they have been widely studied and applied [1-5]. In order to improve the performance, the harmonics in air gap flux density is researched to be mitigated or eliminated. The magnet surface optimization is the most common way in RFPM machines with surface mounted permanent magnets (PMs) [6,7]. However the method is seldom adopted in AFPM machines because the arc lengths are unequal at different radii. Instead the Halbach PMs is adopted in [8]. The machine with interior PMs have less eddy current losses in PMs than that with surface mounted PMs, but there is limited amount of work on the axial flux interior permanent magnet (AFIPM) machines [9-14]. For most interior permanent magnet (IPM) machines, the non-uniform air gap is adopted to achieve a sinusoidal distributed air gap flux density and back electromotive force (EMF) waveform [15-19], and the best shape of rotor surface is revealed in [19] theoretically. Flat-embedded magnet technique is proposed in [20] in which way a pulse-width modulation technique is adopted to optimize the shape of the iron surface. Nevertheless, the rotor surface design is hard to be adopted in axial flux interior permanent magnet (AFIPM) machines because their different lamination way of iron cores from conventional RFPM machines, unless using special material which has easy machinability and high magnetic permeability [14]. The air-gap flux density is very important in electrical machines, because it is closely related to many of the machine's properties such as iron losses, torque ripple and vibration. In order to achieve the best performance in different aspects, we need focus on different harmonic contents. Total harmonic distortion (THD), as a well-known harmonic evaluation tool, can also be selected as an optimization objective [14,18]. The 3D analysis and finite element method (FEM) simulation are often adopted in the design and study of AFPM machines, but they are very 
complex and time-consuming for the initial design, so the quasi-3D and 2D equivalent methods are widely applied [21-23]. Meanwhile the magnetic equivalent circuit method is considered to be a good compromise between computation time and accuracy compared with the magnetic field analysis based on the solution of Maxwell's equations or finite element method (FEM). The magnetic equivalent circuit method is also widely used in AFPM machines [24,25].

In this paper, the two-layer spoke-type (TLST) AFIPM machine is proposed. The optimization of the air gap flux density can be realized by adding simple flux barriers, in which way there is no need to change the surface of the rotor. The magnetic equivalent circuit method based on 2D equivalent model is adopted to analyze the TLST AFIPM machine. An optimization design process of the TLST permanent magnet is proposed to save the design time. THD minimization of air-gap flux density is selected from a few optimization objectives to verify the proposed structure and this design process. The optimization effects on back EMFs and stator iron losses gotten by 3D finite element method (FEM) simulation are also revealed.

\section{Structure and Optimization Principle of TLST AFIPM Machines}

\subsection{Structure of TLST AFIPM Machines}

Single-stator double-rotor (SSDR) and double-stator single-rotor (DSSR) are the most common structures applied in AFPM machines to balance the axial force between stator and rotor. In this paper, a 20-poles-24-slots (half side in axial direction) DSSR machine is studied as an example. The TLST PM can be regarded as a narrow PM and a wide PM combined along axial direction. The cross sectional view of the permanent magnet at a certain radius in TLST AFIPM machines is a combination of two rectangles, instead of one in spoke-type (ST) AFIPM machines. The differences of the rotor (half side in axial direction) between ST permanent magnets and TLST permanent magnets are shown in Figure 1. Simple flux barriers are also added to lead the flux in the rotor iron. The 2D view of the TLST AFIPM machine with flux barriers at average radius which is also the 2D FEM simulation model, is shown in Figure 2.

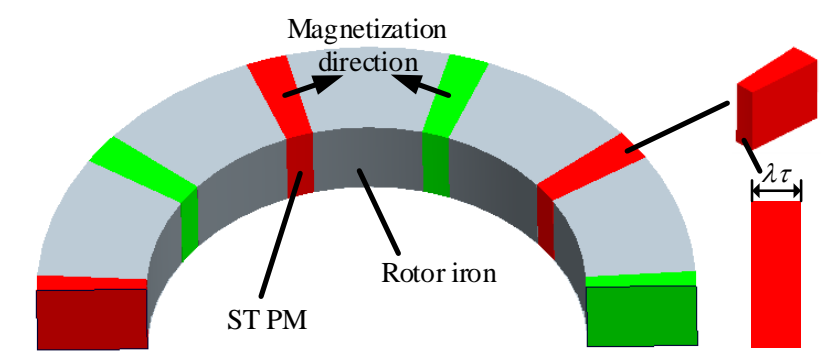

(a)

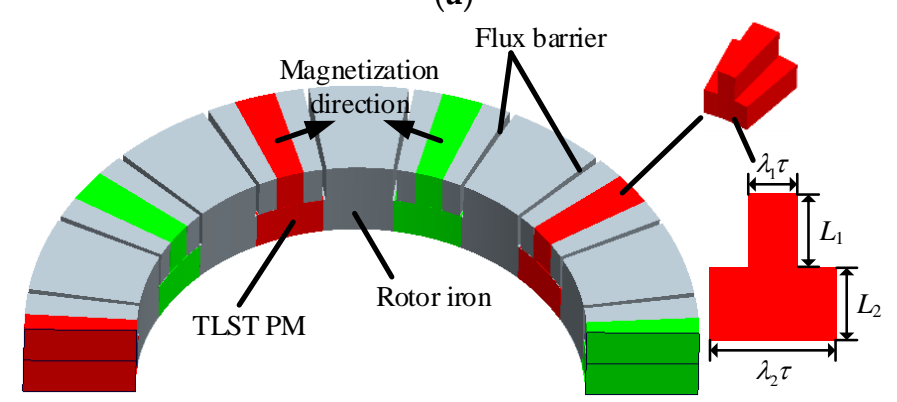

(b)

Figure 1. Structure of the rotor (half side in axial direction): (a) rotor with spoke-type (ST) permanent magnets; (b) rotor with two-layer spoke-type (TLST) permanent magnets and flux barriers. 


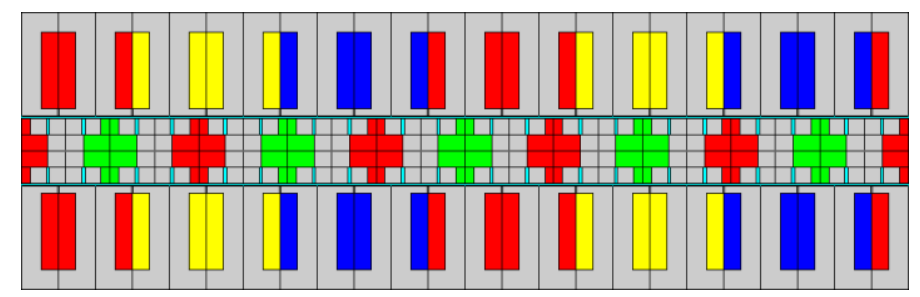

Figure 2. 2D view of the TLST axial flux interior permanent magnet (AFIPM) machine with flux barriers (2D finite element method (FEM) simulation model).

In Figure $1 \tau$ is the pole pitch, $\lambda$ is the ratio of arc length of PM to pole pitch, $\lambda_{1}$ is the ratio of arc length of narrow PM to pole pitch, $\lambda_{2}$ is the ratio of arc length of wide PM to pole pitch, $L_{1}$ is the axial length of narrow PM, $L_{2}$ is the axial length of wide PM, the axial length of half side in axial direction of the rotor is $L=L_{1}+L_{2}, k$ is the length ratio of narrow PM to the total length of PM, that is, $k=L_{1} /\left(L_{1}+L_{2}\right)$.

\subsection{Air Gap Flux Density Optimization Principle of TLST AFIPM Machines}

In common, the scalar magnetic potential is expressed as $\varphi=0$ in the inner stator surface. The scalar magnetic potential of the outer rotor surface is expressed as $\varphi=\varphi_{0}$ for interior permanent magnet (IPM) machines [14]. As a result, the non-uniform air gap, as shown in Figure 3a, is often adopted to optimize the rotor surface.

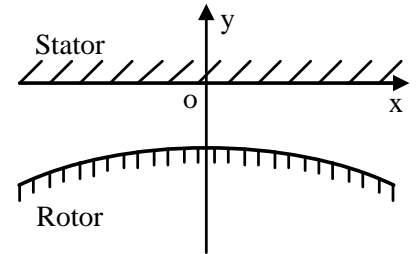

(a)

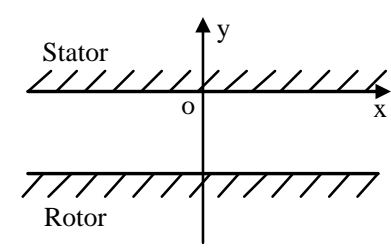

(b)

Figure 3. The category of the air gap: (a) non-uniform air gap; (b) uniform air gap.

For the uniform air gap whose length is $\delta$, the scalar magnetic potential of the inner stator surface is expressed as $\varphi=0$. If the scalar magnetic potential of the outer rotor surface is no longer a constant $\varphi_{0}$ but a variable $\varphi_{0} \sin \left(\frac{\pi}{\tau} x\right)$, the boundary conditions of the air gap area will be expressed as (1).

$$
\left\{\begin{array}{c}
\varphi=0 \quad y=0 \\
\varphi=\varphi_{0} \sin \left(\frac{\pi}{\tau} x\right) \quad y=-\delta
\end{array}\right.
$$

In the air gap, the scalar magnetic potential is described by Laplace's equation

$$
\frac{\partial^{2} \varphi}{\partial x^{2}}+\frac{\partial^{2} \varphi}{\partial y^{2}}=0
$$

The solutions is

$$
\varphi=-\frac{\varphi_{0}}{\sinh \left(\frac{\pi}{\tau} \delta\right)} \sin \left(\frac{\pi}{\tau} x\right) \sinh \left(\frac{\pi}{\tau} y\right) .
$$

The air gap magnetic flux density can be given as

$$
\left\{\begin{array}{c}
B_{x}=-\mu_{0} \frac{\partial \varphi}{\partial x}=\mu_{0} \frac{\pi \varphi_{0}}{\tau \sinh \left(\frac{\pi}{\tau} \delta\right)} \cos \frac{\pi}{\tau} x \sinh \frac{\pi}{\tau} y \\
B_{y}=-\mu_{0} \frac{\partial \varphi}{\partial y}=\mu_{0} \frac{\pi \varphi_{0}}{\tau \sinh \left(\frac{\pi}{\tau} \delta\right)} \sin \frac{\pi}{\tau} x \cosh \frac{\pi}{\tau} y
\end{array} .\right.
$$


It illustrates that when the scalar magnetic potential is a sinusoidal expression, the air gap magnetic flux density will be a sinusoidal expression. However the magnetic permeability of the rotor iron is often regarded as infinite when the saturation is neglected. The scalar magnetic potential will not be a sinusoidal expression. In this paper, simple flux barriers are added to lead flux in the rotor with TLST permanent magnets. The thicknesses of PMs in different magnetic circuits are also different. As a result, the scalar magnetic potential of different parallel magnetic circuits along the rotor surface will be different. As the sinusoidal waveform can be approximated by the stepped waveform, the harmonics in air gap flux density will be mitigated or eliminated by this way.

\subsection{The Comparison between ST and TLST AFIPM Machine}

The directly solving of the rotor magnetic field of IPM machines is very hard and complex, so the 2D FEM simulation is adopted. The analysis of air gap flux density reflects the optimization effect. The 2D FEM simulation model is shown in Figure 2. The air gap flux density waveforms of ST AFIPM machines are shown in Figure $4 \mathrm{a}$ when $\lambda$ is changing. The corresponding fundamental amplitudes and total harmonic distortions (THDs) of air gap flux density waveforms are shown in Figure $4 \mathrm{~b}$. Taking $\lambda_{1}=0.25, \lambda_{2}=0.45$ for example, the TLST AFIPM machines with and without flux barriers are calculated by simulation, too. The air gap flux density waveforms and their corresponding fundamental amplitudes and THDs are shown in Figures 5 and 6 when $k$ is changing.

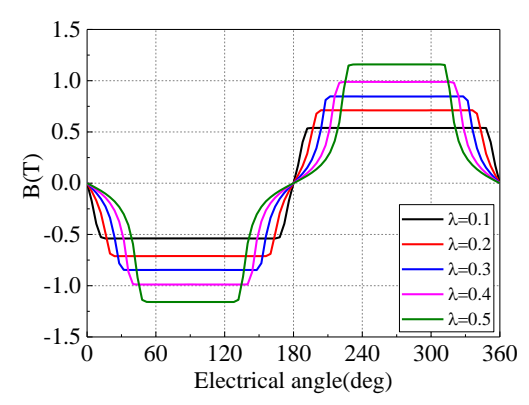

(a)

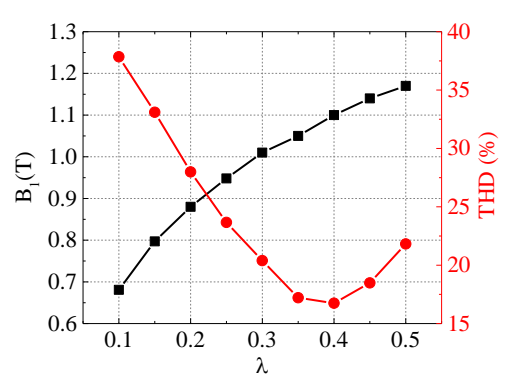

(b)

Figure 4. The air gap flux density waveforms and corresponding fundamental amplitudes and total harmonic distortions (THDs) of ST AFIPM machines: (a) air gap flux density waveforms; (b) fundamental amplitude and THD comparison.

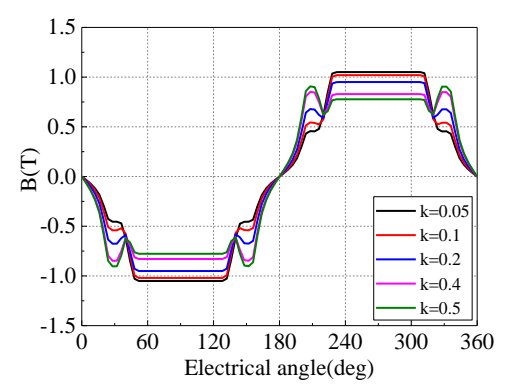

(a)

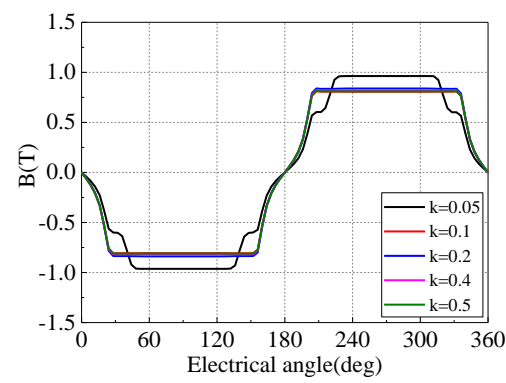

(b)

Figure 5. The air gap flux density waveforms of TLST AFIPM machines with and without flux barriers: (a) machine with flux barriers; (b) machine without flux barriers. 


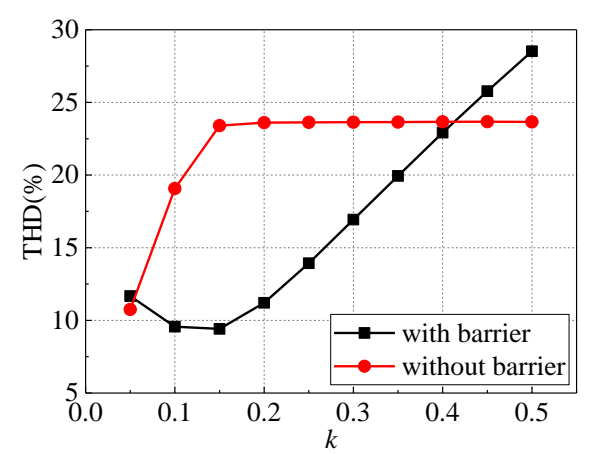

(a)

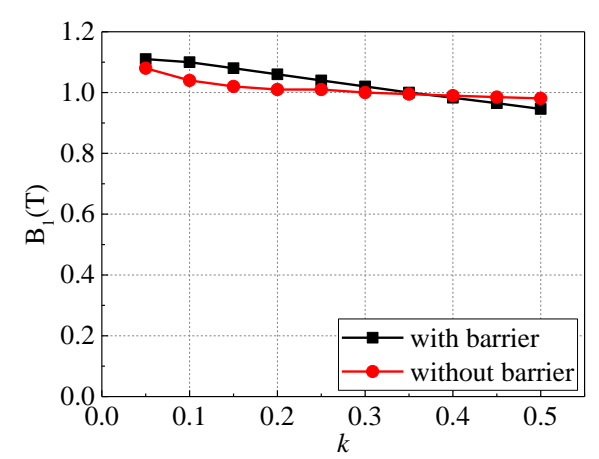

(b)

Figure 6. The comparison of THDs and fundamental amplitudes of air gap flux density of TLST AFIPM machines with and without flux barriers: (a) THD comparison; (b) fundamental amplitude comparison.

Figure 4 shows that the air gap flux density waveforms of ST AFIPM machines are similar to square waves, and THDs of them are more than $16 \%$. Figure 5 shows that the air gap flux density waveforms of TLST AFIPM machines with flux barriers are step shape when $k$ is chosen properly. Those without flux barriers are step shape with only small length ratios. Figure 6a illustrates that the THD increases first and fix around a constant for the machine without flux barriers and the THD decreases first and increases for the machine with flux barriers when $k$ is increasing. The reason is that the flux will be uniformly distributed and the scalar magnetic potential will be a constant if there are no flux barriers except $k$ is very small and the iron is saturated. The flux will be leaded and the scalar magnetic potential will be adjusted if there are flux barriers and the air gap flux density can be optimized. The THD of the machine with flux barriers are less than that of the machine without flux barriers, even less than $10 \%$, when $k$ is chosen properly. So only if $k$ is very small the machine without flux barriers will be preferential considering the manufacturing complexity. Figure $6 \mathrm{~b}$ illustrates that for the machine with flux barriers, the fundamental amplitude of air gap flux density is improved when harmonics are mitigated. The comparison shows that the design of TLST permanent magnets with barriers is more effective in air gap flux density optimization. Comparing with the ST AFIPM machine, there are advantages of the TLST AFIPM machine in optimizing the air gap flux density.

The further comparison of two types of magnets considering magnet volume is shown in Tables 1 and 2. For the ST AFIPM machine, $\lambda=0.38$ reaches the lowest THD. For the TLST AFIPM machine, different combinations of $\lambda_{1}, \lambda_{2}$ and $k$ are chosen to get the same magnet volume with the ST AFIPM machine in Table 1 and to get the same fundamental amplitude of air gap magnetic flux density with the ST AFIPM machine in Table 2, respectively. Table 1 illustrates that when the magnet volumes are the same, $B_{1}$ of the TLST AFIPM machine is a little lower than that of the ST AFIPM machine. Table 2 reveals that to get the same $B_{1}$, the TLST AFIPM machine needs a little more permanent magnet than the ST AFIPM machine. However, it should be noted from TLST- 5 and TLST- 6 that more permanent magnet cannot always achieve lower THD.

Table 1. $B_{1}$ comparison at the same volume.

\begin{tabular}{ccccc}
\hline Parameter & ST & TLST-1 & TLST-2 & TLST-3 \\
\hline$\lambda_{1}(\lambda)$ & 0.38 & 0.30 & 0.25 & 0.20 \\
$\lambda_{2}$ & - & 0.392 & 0.400 & 0.407 \\
$k$ & - & 0.13 & 0.13 & 0.13 \\
$\mathrm{~V} / \mathrm{V}_{\mathrm{RPM}}$ & 1 & 1 & 1 & 1 \\
$B_{1}$ & 1.08 & 1.070 & 1.058 & 1.045 \\
$\mathrm{THD}$ & $16.6 \%$ & $12.5 \%$ & $11.3 \%$ & $11.4 \%$ \\
\hline
\end{tabular}


Table 2. Volume comparison at the same $B_{1}$.

\begin{tabular}{ccccc}
\hline Parameter & ST & TLST-4 & TLST-5 & TLST-6 \\
\hline$\lambda_{1}(\lambda)$ & 0.38 & 0.30 & 0.25 & 0.20 \\
$\lambda_{2}$ & - & 0.41 & 0.45 & 0.48 \\
$k$ & - & 0.13 & 0.13 & 0.13 \\
$\mathrm{~V} / \mathrm{V}_{\mathrm{RPM}}$ & 1 & 1.04 & 1.116 & 1.167 \\
$B_{1}$ & 1.08 & 1.08 & 1.08 & 1.08 \\
$\mathrm{THD}$ & $16.6 \%$ & $11.4 \%$ & $9.2 \%$ & $10.8 \%$ \\
\hline
\end{tabular}

When the axial length of the rotor is determined, the air gap flux density is only related to $\lambda$ for the ST AFIPM machine. However it is related to $\lambda_{1}, \lambda_{2}, k$ for the TLST AFIPM machine. The interaction of multi-parameters is very complex, so the optimal design of the TLST permanent magnet is important and it is focused in the next part.

\section{Optimization Design Process}

\subsection{Analysis Model}

As the AFIPM machine proposed in this paper has a symmetrical structure, the magnetic circuit analysis of half side in axial direction is enough. In order to focus on the influence of the TLST permanent magnet on the air gap flux density, the saturation in iron cores and slotting effect are neglected. The main paths of the magnetic flux of one pole at no-load are shown in Figure 7 and the corresponding magnetic equivalent circuit is shown in Figure 8. $\Phi_{1}$ and $\Phi_{2}$ represents the magnetic flux of magnetic circuit No. 1 and magnetic circuit No. 2, respectively.

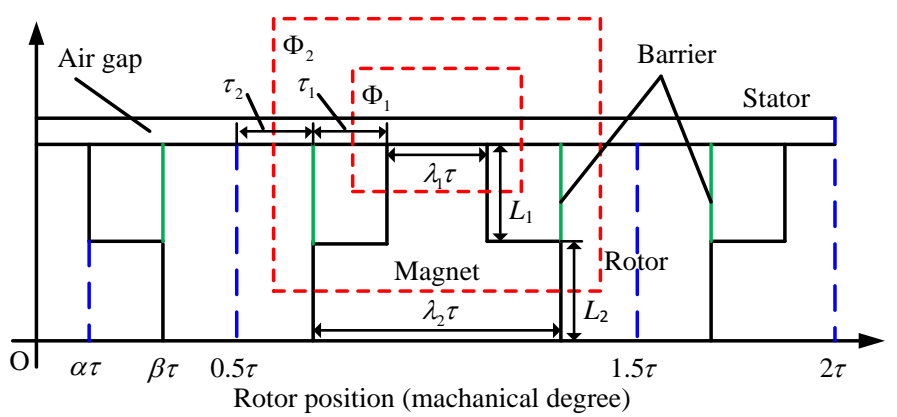

Figure 7. Main paths of the magnetic flux of the machine at no-load.

In Figure $7 \tau_{1}$ and $\tau_{2}$ represents the width of magnetic circuit No. 1 and No. 2 in the air gap, respectively.

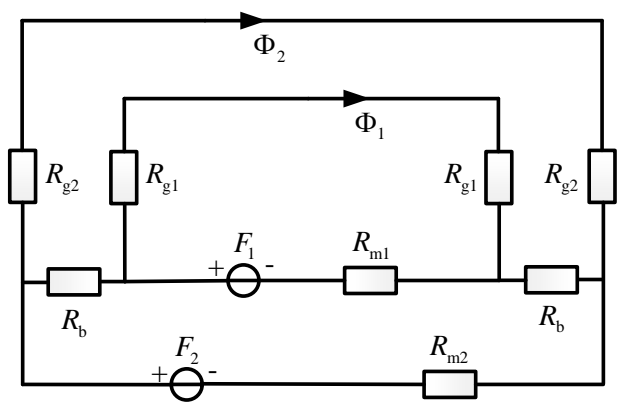

Figure 8. Equivalent magnetic circuit. 
The magnetic equivalent circuit is shown in Figure 8. The elements in the magnetic circuit can be acquired based on the characteristic of the structure.

$$
\begin{gathered}
\left\{\begin{array}{r}
R_{\mathrm{g} 1}=\frac{1}{\beta-\alpha} R_{\mathrm{g}} \\
R_{\mathrm{g} 2}=\frac{1}{0.5-\beta} R_{\mathrm{g}}
\end{array}\right. \\
\left\{\begin{array}{l}
R_{\mathrm{m} 1}=\frac{1}{k} R_{\mathrm{m}} \\
R_{\mathrm{m} 2}=\frac{\beta}{\alpha} \frac{1}{1-k} R_{\mathrm{m}}
\end{array}\right. \\
F_{2}=\frac{\beta}{\alpha} F_{1} \\
\left\{\begin{array}{l}
\Phi_{1}=\frac{F_{1}}{R_{\mathrm{g} 1}+R_{\mathrm{m} 1}} \\
\Phi_{2}=\frac{F_{2}}{R_{\mathrm{g} 2}+R_{\mathrm{m} 2}}
\end{array}\right.
\end{gathered}
$$

$\alpha=0.5 \times \lambda_{1}, \beta=0.5 \times \lambda_{2}, R_{\mathrm{g} 1}$ and $R_{\mathrm{g} 2}$ is the air gap magnetic resistance of magnetic circuit No. 1 and No. 2, respectively, $R_{\mathrm{g}}$ is the magnetic resistance of air gap of one pole, $R_{\mathrm{m} 1}$ and $R_{\mathrm{m} 2}$ is the magnetic resistance of permanent magnet in magnetic circuit No. 1 and No. 2, respectively, $R_{\mathrm{m}}$ is the magnetic resistance of the PM whose arc length is $\lambda_{1} \tau$ and axial length is $\left(L_{1}+L_{2}\right), R_{\mathrm{b}}$ is the magnetic resistance of flux barrier, $F_{1}$ and $F_{2}$ are the magnetic motive forces of narrow and wide PMs, respectively. $\Phi_{1}$ and $\Phi_{2}$ can be got by solving the magnetic circuit shown in Figure 8. $B_{01}, B_{02}$ will be got by

$$
\begin{gathered}
\left\{\begin{array}{c}
B_{01}=\frac{\Phi_{1}}{\tau_{1} l} \\
B_{02}=\frac{\Phi_{2}}{\tau_{2} l}
\end{array}\right. \\
\left\{\begin{array}{l}
\tau_{1}=(\beta-\alpha) \tau \\
\tau_{2}=(0.5-\beta) \tau
\end{array}\right.
\end{gathered}
$$

where $l$ is the radial length of the rotor, that is the difference value between outer radius and inner radius.

\subsection{Determination of Initial Value}

The idealized air gap flux density waveform is shown in Figure 9.

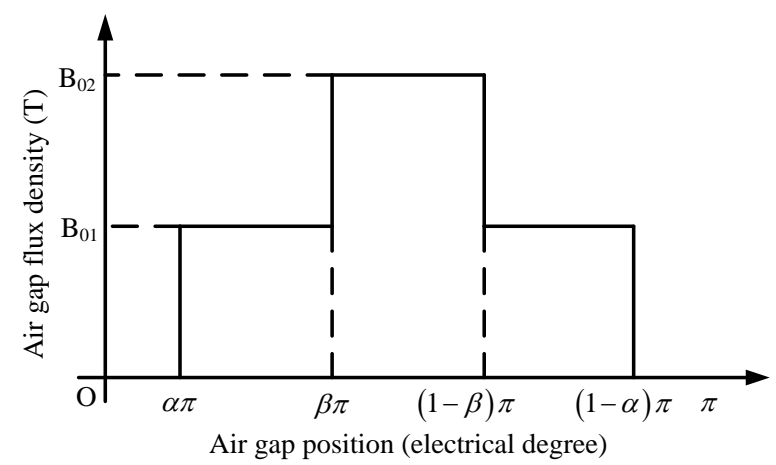

Figure 9. Idealized air gap flux density waveform at no-load.

The expression of the air gap flux density waveform in Figure 9 is

$$
f(x)=\left\{\begin{array}{l}
0 \quad 0 \leq x<\alpha \pi,(1-\alpha) \pi<x \leq \pi \\
B_{01} \quad \alpha \pi \leq x<\beta \pi,(1-\beta) \pi<x \leq(1-\alpha) \pi \\
B_{02} \quad \beta \pi \leq x \leq(1-\beta) \pi
\end{array}\right.
$$


The total harmonic distortion of the air gap flux density shown in Figure 9 can be calculated by (12).

$$
\begin{aligned}
\mathrm{THD} & =\frac{\sqrt{\sum_{n=3,5,7 \ldots} B_{n}^{2}}}{B_{1}} \\
& =\frac{\sqrt{\sum_{n=3,5,7 \ldots}\left[\frac{1}{n} B_{01} \cos n \alpha \pi+\frac{1}{n}\left(B_{02}-B_{01}\right) \cos n \beta \pi\right]^{2}}}{B_{01} \cos \alpha \pi+\left(B_{02}-B_{01}\right) \cos \beta \pi}
\end{aligned}
$$

If

$$
\gamma=\frac{B_{02}-B_{01}}{B_{01}}
$$

the expression (12) can be rewritten as (14).

$$
\mathrm{THD}=\frac{\sqrt{\sum_{n=3,5,7 \ldots}\left[\frac{1}{n} \cos n \alpha \pi+\frac{1}{n} \gamma \cos n \beta \pi\right]^{2}}}{\cos \alpha \pi+\gamma \cos \beta \pi}
$$

The initial value of $\alpha, \beta, \gamma$ can be ensured by (14) basing on the range of $\alpha, \beta, \gamma$, that is $\alpha_{1}, \beta_{1}, \gamma_{1}$.

\subsection{Iterative Computation}

The idealized air gap flux density waveform in Figure 9 is sometimes too simple and idealized, which may lead to some calculation differences from FEM analysis, but it is necessary to fast calculate initial value and narrow the range of $\alpha, \beta, \gamma$. In this paper a more accurate model is proposed, that is the improved air gap flux density waveform as shown in Figure 10. The $\alpha, \beta, \gamma$ can be refreshed based on the $\alpha_{1}, \beta_{1}, \gamma_{1}$ and improved air gap flux density waveform.

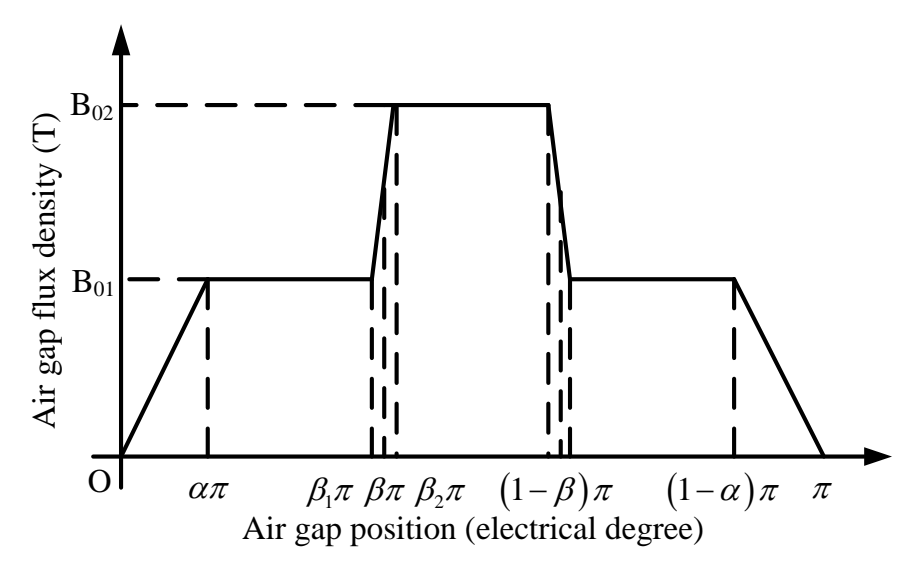

Figure 10. Improved air gap flux density waveform at no-load.

In Figure $100.5 \times\left(\beta_{2}+\beta_{1}\right)=\beta$. The ratio of arc length of flux barrier to pole pitch is $w=\beta_{2}-\beta_{1}$. The expression of the air gap flux density waveform is:

$$
g(x)=\left\{\begin{array}{l}
\frac{B_{01}}{\alpha \pi} 0 \leq x<\alpha \pi \\
B_{01} \alpha \pi \leq x<\beta_{1} \pi \\
\frac{B_{02}-B_{01}}{\left(\beta_{2}-\beta_{1}\right) \pi} x+\frac{B_{01} \beta_{2}-B_{02} \beta_{1}}{\beta_{2}-\beta_{1}} \beta_{1} \pi \leq x<\beta_{2} \pi \\
B_{02} \beta_{2} \pi \leq x<\left(1-\beta_{2}\right) \pi \\
-\frac{B_{02}-B_{01}}{\left(\beta_{2}-\beta_{1}\right) \pi} x \frac{B_{02}-B_{01}+B_{01} \beta_{2}-B_{02} \beta_{1}}{\beta_{2}-\beta_{1}}\left(1-\beta_{2}\right) \pi \leq x<\left(1-\beta_{1}\right) \pi \\
B_{01}\left(1-\beta_{1}\right) \pi \leq x<(1-\alpha) \pi \\
-\frac{B_{01}}{\alpha \pi} x+\frac{B_{01}}{\alpha}(1-\alpha) \pi \leq x \leq \pi
\end{array} .\right.
$$


The total harmonic distortion of the air gap flux density waveform shown in Figure 10 can be calculated by (16).

$$
\begin{aligned}
& \text { THD }=\frac{\sqrt{n=3,5,7, \ldots} B_{n}^{2}}{B_{1}} \\
& =\frac{\sqrt{\sum_{n=3,5,7 \ldots}\left[\frac{1}{n^{2}} \frac{B_{01}}{\alpha} \sin n \alpha \pi+\frac{1}{n^{2}} \frac{B_{02}-B_{01}}{\beta_{2}-\beta_{1}}\left(\sin n \beta_{2} \pi-\sin n \beta_{1} \pi\right)\right]^{2}}}{\frac{B_{01}}{\alpha} \sin \alpha \pi+\frac{B_{02}-B_{01}}{\beta_{2}-\beta_{1}}\left(\sin \beta_{2} \pi-\sin \beta_{1} \pi\right)},
\end{aligned}
$$

that is:

$$
\mathrm{THD}=\frac{\sqrt{\sum_{n=3,5,7 \ldots}\left[\frac{1}{n^{2}} \frac{1}{\alpha} \sin n \alpha \pi+\frac{1}{n^{2}} \frac{\gamma}{\beta_{2}-\beta_{1}}\left(\sin n \beta_{2} \pi-\sin n \beta_{1} \pi\right)\right]^{2}}}{\frac{1}{\alpha} \sin \alpha \pi+\frac{\gamma}{\beta_{2}-\beta_{1}}\left(\sin \beta_{2} \pi-\sin \beta_{1} \pi\right)} .
$$

$\alpha, \beta$ and $\gamma$ based on improved air gap flux density are refreshed till the values are convergent at the $i$ th process. Then the final value of $\alpha, \beta$ and $\gamma$ are determined, that is $\alpha_{i}, \beta_{i}, \gamma_{i}$. Then the TLST permanent magnet dimensions $\lambda_{1}, \lambda_{2}, k$ can be determined. The corresponding optimization process is shown in Figure 11.

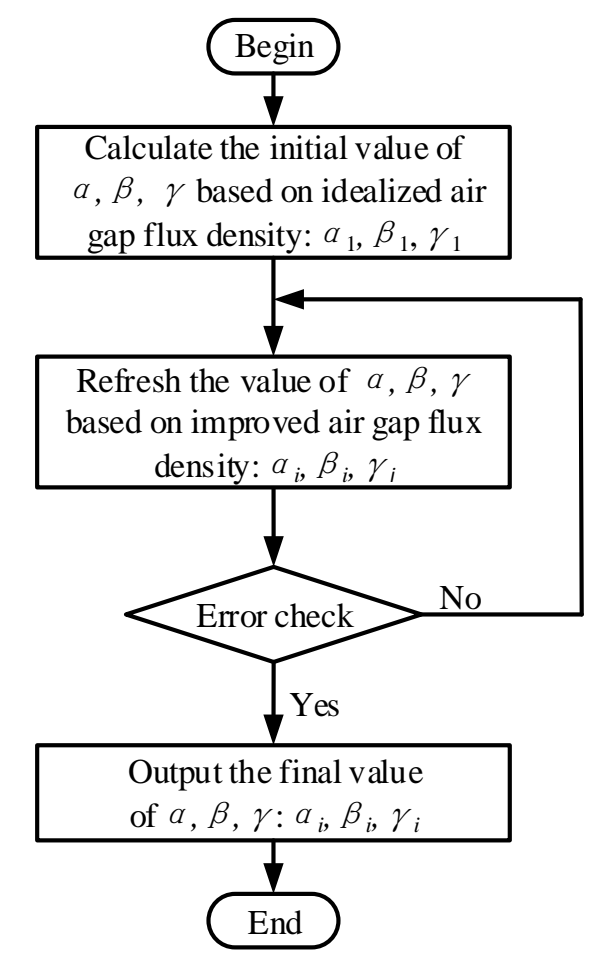

Figure 11. The optimization design process.

\section{Optimal Design Result and Further Analysis}

The proposed optimization design process is adopted to calculate the TLST AFIPM machine whose parameters are shown in Table 3. $\lambda_{1}, \lambda_{2}, k$ can be determined by the proposed optimization process which are the analytical best TLST permanent magnet dimensions, that is $\lambda_{1}=0.24, \lambda_{2}=0.48, k=0.14$. The corresponding THD is $9.66 \%$. Meanwhile the minimum THD gotten by 2D FEM simulation is $9.20 \%$ when $\lambda_{1}=0.25, \lambda_{2}=0.45, k=0.13$ which are the 2D FEM best TLST permanent magnet dimensions. Since the pole arc ratios are the same at different radii for the machine in this paper. Ignoring the end effect, the 2D FEM simulation can be adopted to save time instead of 3D FEM simulation. The comparison of air gap flux density waveforms of these two permanent magnets 
dimensions is shown in Figure 12. Figure 12 illustrates that the difference between waveforms of analytical best design and 2D FEM best design is small.

Table 3. Machine Parameters.

\begin{tabular}{cc}
\hline Parameter & Value \\
\hline Number of stator slots & 24 \\
Number of rotor poles & 20 \\
Pole pitch at average radius (mm) & 55 \\
Axial length of rotor(half side in axial direction) $(\mathrm{mm})$ & 20 \\
Thickness of flux barrier (mm) & 3 \\
Air gap length (mm) & 2 \\
PM type & N38EH \\
Silicon steel sheet type & 35WW250 \\
\hline
\end{tabular}

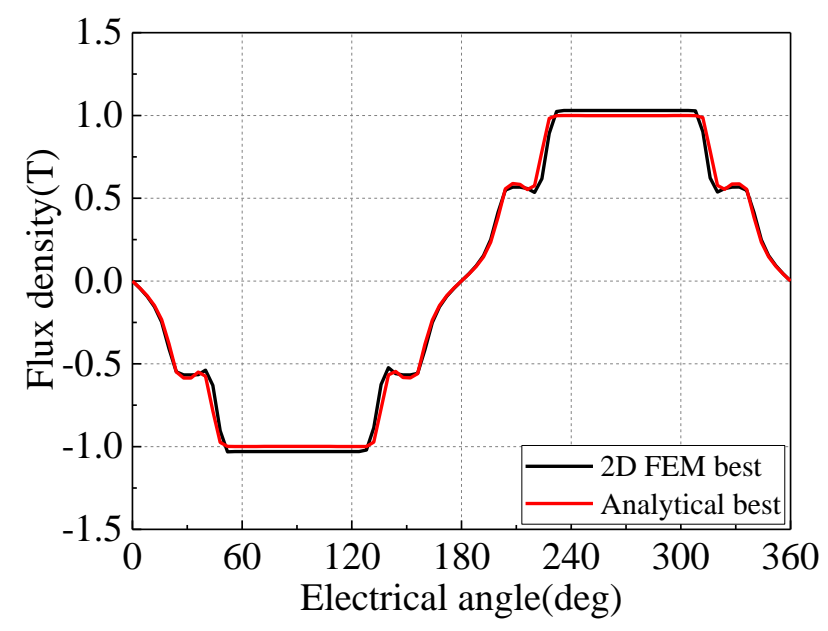

Figure 12. Comparison of air gap flux density waveforms.

The results gotten by 2D FEM simulation with scanning multiple parameters are shown in Figure 13. It is time consuming but it illustrates the variation of THD when $\lambda_{1}, \lambda_{2}, k$ are changed. A three-dimensional space is constituted by the three variables and the color of every point represents the THD of corresponding TLST permanent magnet dimensions. The span of suitable points depends on the THD restriction. The analytical best and 2D FEM best TLST permanent magnet dimensions are shown in Figure 13b. The point which represents the 2D FEM best dimensions is at the center of the cube. The point represents the analytical best dimensions is at the crossover point of cross sections of $\lambda_{1}=0.24, \lambda_{2}=0.48$ and $k=0.14$. The difference of THDs is less than $0.5 \%$ which is acceptable and means the FEM simulation can be replaced by the proposed optimization design process. As a result, the calculation time can be saved compared with the FEM simulation in which way multiple parameters are needed to be scanned. 


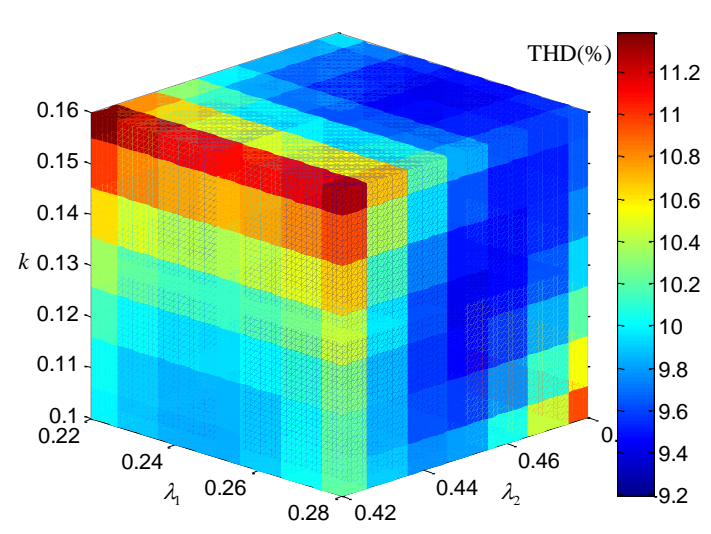

(a)

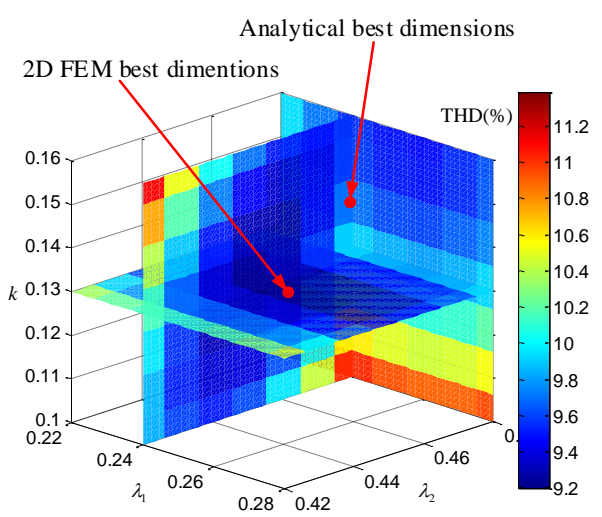

(b)

Figure 13. 2D FEM simulation results gotten by scanning multiple parameters: (a) database cube gotten by 2D FEM simulation; (b) the point of the analytical best dimensions and the point of the 2D FEM best dimensions.

For the TLST AFIPM machine, the fundamental amplitude of air gap flux density is 1.08T. Compared with the ST AFIPM machine whose fundamental amplitude is the same and the THD is $16.6 \%$, the THD of TLST AFIPM machine is decreased to $9.2 \%$. The air gap flux density is improved by TLST AFIPM machine remarkably. The air gap flux density will be affected by the slotting effect actually, especially for the machine with fractional-slot concentrated windings, so the back EMF waveforms are always adopted for comparison instead. 3D FEM simulation model and the magnetic flux density distribution at no-load of the TLST AFIPM machine with flux barriers are shown in Figure 14. The back EMF waveforms gotten by 3D FEM simulation and their Fourier analysis results at no-load are compared in Figures 15 and 16. The THD of back EMF is 7.5\% of the ST AFIPM machine and $5.35 \%$ of the TLST AFIPM machine. Obviously the air gap flux density and back EMF are improved by the optimization of permanent magnets. The root-mean-square (RMS) values of back EMF of the TLST and ST AFIPM machine are $144 \mathrm{~V}$ and $147 \mathrm{~V}$, respectively. The fundamental amplitudes of them are $203 \mathrm{~V}$ and $207.5 \mathrm{~V}$, respectively. This small difference results from the edge effect not considered in the $2 \mathrm{D}$ model.

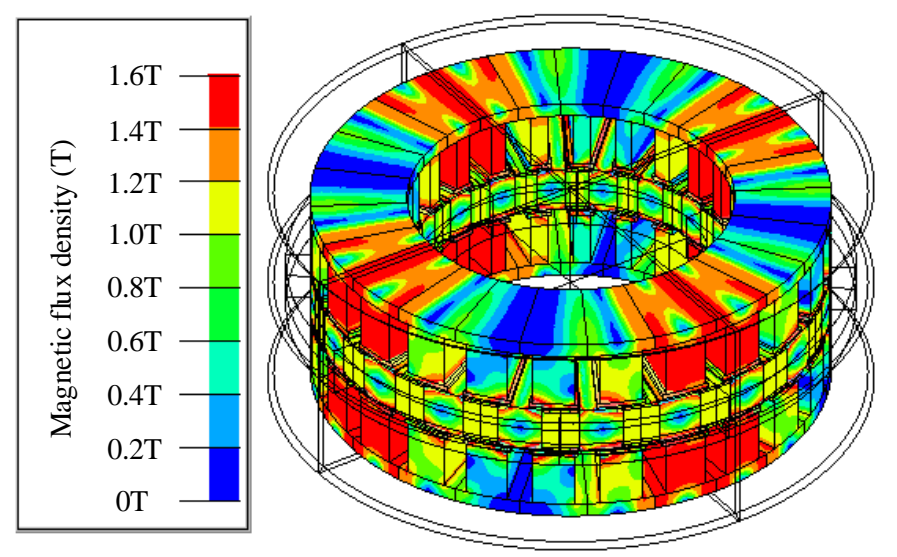

Figure 14. 3D finite element method (FEM) simulation model and the magnetic flux density distribution at no-load of the TLST AFIPM machine with flux barriers. 


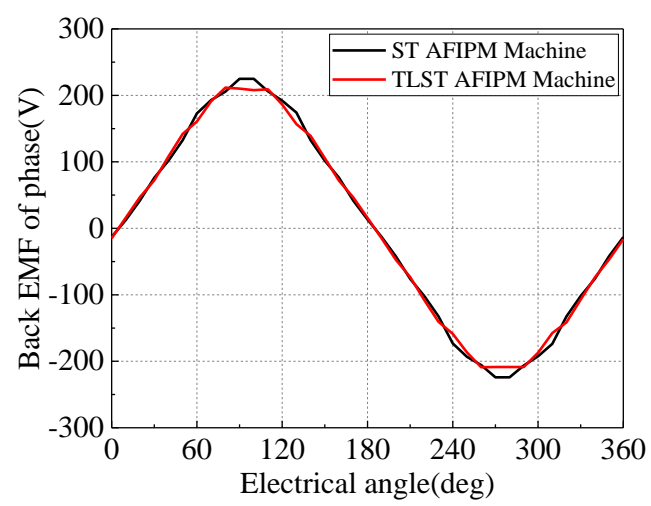

Figure 15. Back electromotive force (EMF) waveforms of the two machines.

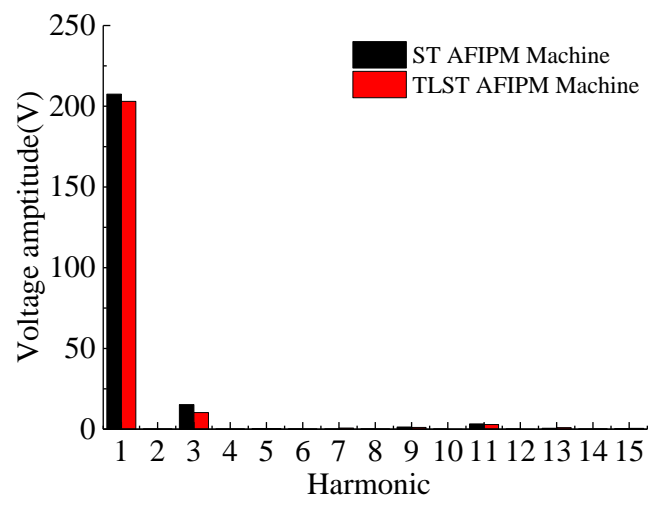

Figure 16. The comparison of harmonics of back EMF waveforms.

Stator iron losses are caused by the harmonics of air gap flux density at no-load. The stator iron losses will be decreased when the THD of air gap flux density is decreased. For example, the TLST AFIPM machine is about $6.2 \%$ less than that of the ST AFIPM machine at $6000 \mathrm{rpm}$. Stator iron losses at no-load gotten by 3D FEM simulation are shown in Figure 17.

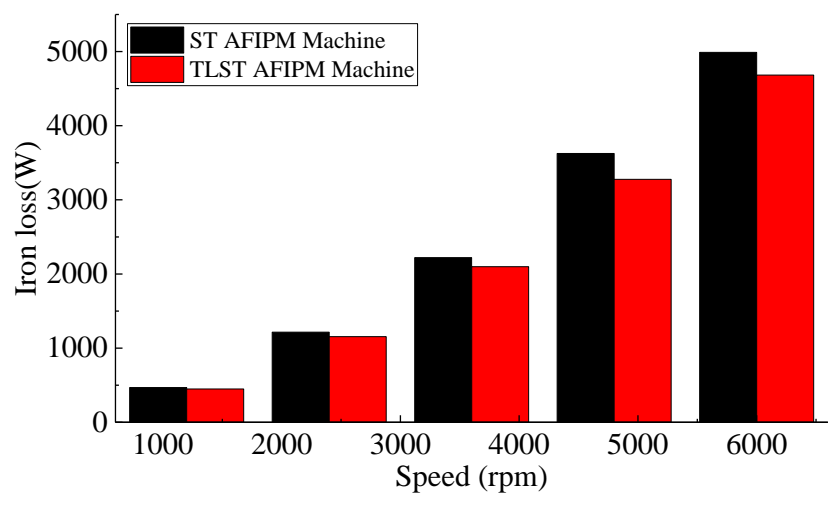

Figure 17. Stator iron losses at different speed at no-load.

\section{Conclusions}

In this paper, the two-layer spoke-type AFIPM machine with flux barriers is proposed. The novel design provides a new way to optimize the air gap flux density avoiding changing the surface of the rotor. 
An optimization design process based on magnetic equivalent circuit combined with idealized and improved air gap flux density waveform is proposed. The THD difference between the analytical best and 2D FEM best TLST permanent magnet dimensions is less than $0.5 \%$, which means the FEM simulation can be replaced by the proposed optimization design process. The calculation time can also be saved by avoiding an excess of FEM simulations.

3D FEM simulation is adopted to verify the optimization effects on back EMF at no-load, which also confirms the optimization effects on air gap flux density indirectly. The stator iron losses are also reduced when the harmonics of the air gap flux density are decreased.

Acknowledgments: The authors would like to thank the support by the National Natural Science Foundation of China (51677039) for funding this work.

Author Contributions: This paper is the results of the hard work of all authors. Feng Chai and Yunlong Bi conceived and designed the proposed method. Yulong Pei built the FEM models and analyzed the data. Yunlong Bi wrote the paper. All authors gave advices for the manuscripts.

Conflicts of Interest: The authors declare no conflict of interest.

\section{References}

1. Kappatou, J.C.; Zalokostas, G.D.; Spyratos, D.A. 3-D FEM analysis, prototyping and tests of an axial flux permanent-magnet wind generator. Energies 2017, 10, 1269. [CrossRef]

2. Huang, Y.; Guo, B.; Hemeida, A.; Sergeant, P. Analytical modeling of static eccentricities in axial flux permanent-magnet machines with concentrated windings. Energies 2016, 9, 892. [CrossRef]

3. Wang, X.; Xu, S.; Li, C.; Li, X. Field-Weakening Performance Improvement of the Yokeless and Segmented Armature Axial Flux Motor for Electric Vehicles. Energies 2017, 10, 1492. [CrossRef]

4. Yang, Y.P.; Shih, G.Y. Optimal Design of an Axial-Flux Permanent-Magnet Motor for an Electric Vehicle Based on Driving Scenarios. Energies 2016, 9, 285. [CrossRef]

5. Zhao, J.; Li, B.; Gu, Z. Research on an axial flux PMSM with radially sliding permanent magnets. Energies 2015, 8, 1663-1684. [CrossRef]

6. Laskaris, K.I.; Kladas, A.G. Permanent-magnet shape optimization effects on synchronous motor performance. IEEE Trans. Ind. Electron. 2011, 58, 3776-3783. [CrossRef]

7. Chai, F.; Liang, P.; Pei, Y.; Cheng, S. Magnet Shape Optimization of Surface-Mounted Permanent-Magnet Motors to Reduce Harmonic Iron Losses. IEEE Trans. Mag. 2016, 52, 6301304. [CrossRef]

8. Jin, P.; Yuan, Y.; Xu, Q.; Fang, S.; Lin, H.; Ho, S.L. Analysis of Axial-Flux Halbach Permanent-Magnet Machine. IEEE Trans. Mag. 2015, 51, 8207404. [CrossRef]

9. Zhao, W.; Lipo, T.A.; Kwon, B.I. A Novel Dual-Rotor, Axial Field, Fault-Tolerant Flux-Switching Permanent Magnet Machine with High-Torque Performance. IEEE Trans. Mag. 2015, 51, 8112204. [CrossRef]

10. Zhao, F.; Lipo, T.A.; Kwon, B.I. A novel dual-stator axial-flux spoke-type permanent magnet vernier machine for direct-drive applications. IEEE Trans. Mag. 2014, 50, 8104304. [CrossRef]

11. Zhao, W.; Lipo, T.A.; Kwon, B.I. Comparative study on novel dual stator radial flux and axial flux permanent magnet motors with ferrite magnets for traction application. IEEE Trans. Mag. 2014, 50, 8104404. [CrossRef]

12. Zhao, W.; Lipo, T.A.; Kwon, B.I. Design and analysis of a novel dual stator axial flux spoke-type ferrite permanent magnet machine. In Proceedings of the IEEE 39th Annual Conference Industral Electronics Society, Vienna, Austria, 10-13 November 2013; pp. 2714-2719.

13. Chirca, M.; Breban, S.; Oprea, C.; Radulescu, M. Comparative design analysis of ferrite-permanent-magnet micro-wind turbine generators. In Proceedings of the 2015 International Aegean Conference on Electrical machines and Power Electronics ACEMPOPTIM-ELECTROMOTION Joint Conference, Side, Turkey, 2-4 September 2015; pp. 687-692.

14. Aydin, M.; Gulec, M. A New Coreless Axial Flux Interior Permanent Magnet Synchronous Motor with Sinusoidal Rotor Segments. IEEE Trans. Mag. 2016, 52, 8105204. [CrossRef]

15. Hwang, K.Y.; Rhee, S.B.; Yang, B.Y.; Kwon, B.I. Rotor pole design in spoke-type brushless DC motor by response surface method. IEEE Trans. Mag. 2007, 43, 1833-1836. [CrossRef] 
16. Park, Y.U.; Cho, J.H.; Chung, D.H.; So, J.Y.; Kim, D.K. A rotor shape design of interior PM motor for reducing cogging torque in electric air-conditioning system of HEV. In Proceedings of the 2013 International Conference on Electrical Machines and Systems (ICEMS), Busan, Korea, 26-29 October 2013; pp. 1139-1143.

17. Hwang, K.Y.; Jo, J.H.; Kwon, B.I. A study on optimal pole design of spoke-type IPMSM with concentrated winding for reducing the torque ripple by experiment design method. IEEE Trans. Mag. 2009, 45, 4712-4715. [CrossRef]

18. Liu, M.; Han, Z.; Pei, Y.; Shi, P. Optimization of permanent magnet motor air-gap flux density based on the non-uniform air gap. In Proceedings of the 2013 International Conference on Mechatronic Sciences, Electric Engineering and Computer (MEC), Shengyang, China, 20-22 December 2013; pp. 3422-3426.

19. Chai, F.; Liang, P.; Pei, Y.; Cheng, S. Analytical method for iron losses reduction in interior permanent magnet synchronous motor. IEEE Trans. Mag. 2015, 51, 6301404. [CrossRef]

20. Chaithongsuk, S.; Nahid-Mobarakeh, B.; Caron, J.P.; Takorabet, N.; Meibody-Tabar, F. Optimal design of permanent magnet motors to improve field-weakening performances in variable speed drives. IEEE Trans. Ind. Electron. 2012, 59, 2484-2494. [CrossRef]

21. Vansompel, H.; Sergeant, P.; Dupre, L. A multilayer 2-D-2-D coupled model for eddy current calculation in the rotor of an axial-flux PM machine. IEEE Trans. Energy Convers. 2012, 27, 784-791. [CrossRef]

22. Jang, S.M.; Koo, M.M.; Park, Y.S.; Choi, J.Y.; Lee, S.H. Characteristic analysis on the influence of misaligned rotor position of double-sided axial flux permanent magnet machine and experimental verification. IEEE Trans. Mag. 2012, 48, 2941-2944. [CrossRef]

23. Tiegna, H.; Amara, Y.; Barakat, G. A new quasi-3-D analytical model of axial flux permanent magnet machines. IEEE Trans. Mag. 2014, 50, 7020204. [CrossRef]

24. Huang, Y.; Zhou, T.; Dong, J.; Lin, H.; Yang, H.; Cheng, M. Magnetic Equivalent Circuit Modeling of Yokeless Axial Flux Permanent Magnet Machine with Segmented Armature. IEEE Trans. Mag. 2014, 50, 8104204. [CrossRef]

25. De Donato, G.; Giulii Capponi, F.; Caricchi, F. No-load performance of axial flux permanent magnet machines mounting magnetic wedges. IEEE Trans. Ind. Electron. 2012, 59, 3768-3779. [CrossRef]

(C) 2017 by the authors. Licensee MDPI, Basel, Switzerland. This article is an open access article distributed under the terms and conditions of the Creative Commons Attribution (CC BY) license (http:/ / creativecommons.org/licenses/by/4.0/). 